\title{
Problems and Complexities in Rural Schools: Challenges of Education and Social Development
}

\author{
Pierre du Plessis
}

University of Johannesburg

Doi:10.5901/mjss.2014.v5n20p1109

\begin{abstract}
One of the greatest challenges South Africa faces is rural poverty and education. Rural school principals face a number of challenges that are unique to their environment. These challenges stem from a number of sources, from within the school division structure from a community perspective, and from the school setting itself. After eighteen years of democracy, rural schooling has shown little improvement. Collectively the article illustrates the complexity, interconnectedness and intractability of the challenges that face rural schools and education in South Africa. The article explores the responses of school principals of rural schools in the Mpumalanga province and explores the responses of school principals of rural schools in the Mpumalanga province are especially in the Nelspruit and White River areas. The research is focused in grounded theory building, with the focus on the challenges and complexities of principals in the areas.
\end{abstract}

Keywords: Rural Schools, principalship, Social Development, Poverty, Education

\section{Introduction}

The role of the rural principal is complex and multi-layered. The introduction of educational changes has shown pronounced differences.

Some schools found the educational changes more challenging than others. Schools that were cited to have been exposed to gross challenges in the implementation and sustenance of change are the rural schools in South Africa (Msila, 2010). In the past there were always concerns that South Africa's rural areas were marginalised and underresourced (ANC, 1995).

While it is widely recognised that the role of the principal is a pivotal one in education (Polischuk, 2002; Mulford \& Johns, 2004; Peters \& Le Cornu, 2004), there appears to be little research undertaken and reported on the leadership and management of schools from the perspective of the day-to-day lived and working experiences of principals in rural contexts.

Rural areas are characterised by various factors that negatively influence that delivery of quality education. Typically rural areas are remote and relatively underdeveloped. As a result, many rural communities and their schools are poor and disadvantaged, lacking basic infrastructure for sanitation, water, roads and other transport, electricity and information and communication technology. The socio-economic realities of rural areas put learners in rural schools at a disadvantage.

Functionally illiterate and innumerate parents are mainly found in our rural areas. Our apartheid past had a lot to do with the fact that these parents lacked the opportunities, development and resources that one would normally find in a more affluent community. In addition, many rural communities lack the professional help, and support, governance structures, books and learning materials that they need to provide the necessary support and care for learners.

The Constitution (South Africa, 1996), and the South African Schools Act (South Africa, 1996) and various policy documents say that all South African learners should have access to the same quality of learning and teaching, similar facilities and equal educational opportunities. However, this is not yet the case. Many of these problems are linked to socio-economic factors such as poverty and unemployment, and also have a direct influence on the quality of education that is available to children and the role the principal should play under these circumstances.

\section{Rural Schools - Background}

Progress in achieving the goals of Education for all programmes and the Millennium Development Goals is very slow. Promoting rural development and schooling must go beyond deficit approaches. From the second half of the twentieth 
century, the literature on rural education tends to emphasise histories and structures that have created conditions and circumstances of oppression", depravation, disadvantage and deficit. In similar deficit terminology, people in rural areas are often stereotyped in ways that emphasise their powerlessness.

As schools in South Africa and specifically in the rural communities of Mpumalanga strive to overcome many problems and withstand rural hardship in order to enhance the culture of learning, issues of self-managing and educational resiliency have become increasingly important as challenges facing South Africa. Principals feel disclosed and alienated from debates about education policy-making. There is an on-going consensus that principals are marginalised and ignored by education bureaucracies. Rural principals feel that there is a sense that the system is not set up to assist, but rather the system is there to mandate, appraise and control when expectations are not met (Starr \& White, 2008). Principals are absorbed with the extra requirements of their existing work lives. They argue they are too busy to engage with reform, as the use of personnel time is valuable.

Resources are difficult to obtain despite increasing learning support needs as homogeneity decreases in some populations. Even if funding submissions are successful, there is more work to be done. Principals see their role as instructional leaders. Principals in rural schools do not have the luxury of having deputy principals and administrative support in undertaking external demands.

Further the side lining of educational matter and unrealistic expectations are a burden on principals. The increase in responsibility also causes an increase in managerial tasks, feeling of isolation, rising stress levels, and a decrease in professional satisfaction. Wallin \& Reimer (2008) write while rural scholars and educational stakeholders believe rural schools should serve the local community interests conflicts still exists over the purpose of schooling. Rural schools, according to Wright (2007), serve a vital role in recreating communities in highly mobile, industrialised society. Further, according the Wallin \& Reimer, rural schools are often plagued with educational problems such as (a) isolation from specialised services; (b) limited accessibility to quality staff, development and university services; (c) teacher shortages; and (d) decreasing enrolment which leads to decreased funding.

Often times when studies are presented on school district issues, the circumstances of rural schools are overlooked. As a result, rural schools are not included in school improvement plans across all school systems.

While the South African Schools Act of 1996 requires that schools and learners should be developed on an equal basis, these are massive historical inequalities in the rural communities of Mpumalanga which cannot be addressed overnight.

Principals in rural schools face many challenges and problems every day. This article wants to address these challenges and complexities which principals face in rural schools in Mpumalanga.

\subsection{Rural Schools Defined}

The definition of rural still eludes us because the term is ambiguous and the distinction with urban tend to be arbitrary, thus no concrete definition has been agreed upon. It should be noted that South Africa has diverse rural areas and therefore certain social, economic, educational and cultural factors need to be considered in enhancing the definition of rural education. Rural schools are the schools in the outskirts of the country. Some use the concept synonymously with the concept farm school or small school.

The following featured are examples of the rural profile (UNESCO, 2005):

○ Distance to towns;

- Topography, (conditions of roads, bridges to school, etc);

- Access to information technology;

- Transport infrastructure (roads, buses, taxis);

- Access to services and facilities (electricity, water, sanitation);

- The health , educational and economic status of the community;

- Access to lifelong learning services;

- Social conditions in the community;

- Activities of political and civil society organisation.

\section{Methodology}

The study was conducted in Mpumalanga in the Nelspruit and White River rural schools, and the study comprised a qualitative exploration of the challenges and problems that principals face in the development of rural schools and also what can and should be done to improve schools in the rural areas. 
Henning, Van Rensburg \& Smit (2004, p36) define methodology as a "coherent group of methods that complement one another and have the goodness of fit to deliver data and findings that reflect the research question and suit the purpose".

Qualitative research "seeks meaning and contributed to theory development by preceding inductively (Miller \& Brewer, 2003, p193). Qualitative methods have been used because the main objective of this research is to gain understanding about how principals of rural schools view their problems and complexities and how it impacts on development in rural schools.

The research was situated in an interpretive orientation. According to Terreblanche \& Durheim (1999), the interpretive researcher's purpose is to gain understanding of situations that are complex and indicates that ..."the central endeavour in the interpretive paradigm is to understand the subject of human experience". Working in this paradigm opens the opportunity to find out how respondents understand the challenges and problems facing rural schools, based on their lived experience rather than theoretical knowledge.

Elements of an interpretive approach as a method are present when reality is studied by looking at participants' definition of the situation. Nevertheless according to Henning et al (2004), the interpretive approach assumes that knowledge is not only constructed by looking at phenomena but by descriptions of people's intentions, beliefs, values and reasons, meanings and self-understanding.

The study included eight (8) principals, five (5) from secondary and three (3) from primary schools. All these schools are historically black and all situated in rural areas. The choice of these schools was that they shared common features such as poverty, low morale amongst teachers, lack of resources, absence of parental and community engagement, safety problems, transport and curriculum challenges.

Semi-structured interviews were the main data collection tools. These allowed for in-depth probing and extended responses. Questions focussed on how respondents experienced the challenges and problems they face to improve the development of their schools and community. The researcher made every effort to encourage respondents to share their challenges and problems, but also their successes and to refer to lived experiences and narrate lived examples of the perceptions they shared.

\section{Research Findings}

In presenting the findings, codes (P1 - P8) are used to distinguish the eight principals (respondents). Qualitative data from the interviews are presented, with references to observation data where appropriate. Findings are presented on themes identified as significant challenges and problems hampering principals and schools in the development of rural schools in Mpumalanga.

The themes are:

- Rural areas are not attractive for teachers;

- Marginalization of school principals;

- Constraints of Role Multiplicity;

- Problems of access in rural schools;

- Challenges of technology;

- Curriculum challenges;

- Lack of resources; and

- Challenges of poverty.

\subsection{Rural areas are not attractive for teachers}

Rural schools find it difficult to attract good and suitable teachers, because there are less financial resources available. Brown (2003) opines that the ideal rural teacher at basic level must be prepared to teach multiple grades or subjects, organise extra-curricular activities and adjust well to environment and the community. Notably, it is extremely difficult to find teachers who fit into the rural community.

"Conditions of service, incentives for teachers in rural areas need to be reviewed to make teaching in rural areas more attractive" according to $P 2$. It is extremely difficult to find teachers who fit into the rural community setting, and do not stay for a long period of time. "Usually the teachers who end up staying are either from a rural background or have previous experience with rural communities" according to P5. 
Teachers have expressed concerns about the quality of accommodation (Akyeampong \& Stevens, 2002), classroom facilities, school resources and access to leisure activities (Towse, et el. 2002). According to P7 "teachers see rural areas as a stumble block for professional advancement". Teachers in rural areas are less likely to have opportunities to engage in other professional development activities (Hedges, 2000).

Hedges (2002) describe the reluctance of teachers to accept a rural position thus:

There is a profound fear among newly trained teachers with a modern individualistic outlook that if you spend too much time in an isolated village without access to further education, you become "a village man".

"There is a need for school administrators to have adequate knowledge of rural background before posting teachers who can fit into the school and community, and who will stay on the job" according to P6.

Problems in supporting newly qualified teachers and a lack of career development opportunities in rural settings often combine to make the teachers' effectiveness difficult in comparison with their urban counterparts.

Another problem facing teachers in rural schools has been persistent neglect.

"Politicians and professional educators have focused their attention on urban education, leaving many to assume that all is well in rural schools" according to P3.

Parks \& Sher (1979) attribute this apparent neglect to the perceived lack of political will to develop to rural constituency.

The lack of qualified teachers in many rural schools is simply because teachers do not want to stay in rural areas due to social, professional and cultural isolation. Castle (1995), reflecting in teachers' reluctance to work or stay in rural areas argues that low salaries, lack of access to professional opportunities, and the responsibility to take on multiple duties are the major challenges confronting teachers and effect their decisions to work or stay in rural areas. Owing to the small size of rural schools and communities, there is a smaller pool of applicants and teachers in rural areas, and rural schools have a high teacher turnover rate (De Young, 1991). All this puts a challenge to the principal to retain teachers at a rural school.

\subsection{Marginalization of school principals}

"Principals feels dislocated and alienated from debates about education policy making", said P4. The consensus is that principals are marginalised and ignored by education bureaucracies.

A related issue concerns a lack of professional contact or support. Many principals do not feel supported by the education system at the state or district level. The majority view is that a division exists with those on the inside having very little understanding about rural school life and leadership challenges.

\footnotetext{
"I think district and central education officials feel antipathy towards rural schools" said P3. Comments concerned principals feeling ignored "being on the back foot" being "isolated"/ there is also the sense that the system is not set up to assist principals, but rather to "mandate, appraise, control, and admonish when expectations are not met" according to $P 1$.

"The district and officials brought no understanding of being a principal let alone a rural school principal and that's a criticism" said P2. "It is no good taking problems to the District Office. They will think that you are not coping or tell you what to do" (P6).
}

A lot of emotion is caught up in these statements. The commentary speaks to veiled modes of sanction, punishment, inducement, and coercion (Starr \& White, 2008).

\subsection{Role Multiplicity}

Rural school principals wear many hats (Buckingham, 2003), having to be generalists and straddling a line between the demand of teaching, leadership, and administration. The necessity of teaching multi-grade and ability levels concurrently and the absence of staff such as deputy principals, heads of department, administrative staff and maintenance staff make to job more labour intensive. 
"It is like a clown who is juggling; all the balls and he is dropping some of them" according to P7.

Conflicting role demands and resources constraints create tensions, and principals feel stretched to the limit by dual roles that cannot be executed thoroughly due to a lack of time for any particular task. Role complexity and multifocussed demands, and the worries they create are difficult challenges for rural principals.

P8 describe it in this way:

\begin{abstract}
"You have to constantly be on the front foot. You try and keep up with what the Department or district wants, you have to watch your numbers, [enrolments], you have to keep an ear to the ground to know what's happening in the community that might spill over into the school, and you have to watch how staff in the schools are faring with pressures to do as much as a large school does".
\end{abstract}

Factors such as limited out of class time, now executive staff (school management team), a small teaching team, isolation and thinly spread advisory staff make it difficult for the principal in rural schools who teaches, to keep up with curriculum implementation and documentation let alone new education initiatives.

P4 said "I think the thing that really suffers is instructional leadership as well as your own class". "I have to trust my staff that they are doing the job because I just don't have the time to visit their classes" (P6).

Factors restricting the ability of rural principals who teach every day, to participate in professional support and development activities at their disposal include limited professional development funds, lack of time due to class responsibilities and distance from professional development sites. All teaching principals struggled with taking time away from their class and the expense that their absence generated.

P6 said "one of the problems of rural schools is if you want to take a day off to go to an in-service, you are affecting so many areas."

\title{
4.4 Curriculum Challenges
}

Minority status, poverty, and location of schools are shown to be closely associated with certain curriculum priorities in the research (Alexander, 2002).

While socio-economic status plays an important role (Monk \& Haller, 1998), when controlling for that, the setting had significant effects. Learners from rural schools are offered fewer educational opportunities than learners in urban schools, according to Alspaugh, (1998). In terms of other courses, rural schools have less to offer; fewer elective classes, such as art and computers as well as advanced placement offerings.

"If we want teaching and learning to improve, more emphasis must be placed on curriculum delivery because this is the lifeblood of schooling", according to P7.

With rural schools being deficient on every indicator of material provision - e.g. physical space and amenities such as electricity and running water, libraries and textbooks - it appears as if curriculum issues are almost completely overshadowed by the more immediate and pressing need for resources to enable effective teaching and learning to take place (Harley \& Wedekind, 2002).

"Urban schools are much more resourced than rural schools and we do not get specialised staff to teach computers, for example", said P4.

Curriculum structuring and planning, according to Mulkeen (2005), may also experience some difficulties in rural areas.

Rural schools are less likely to be visited by district officials. "We do not see subject specialists to assist out teachers" (P2), and that is "why we experience a higher absenteeism in our rural areas because the atmosphere is more relaxed and visits by district is less frequent" (P5).

The local community do not monitor teachers. The local community place a value on education, simply because they are less educated themselves, and so feels less able to challenge the authority of teachers.

In order for curriculum planning to be effective, the school curriculum must address the school's needs both at local level and also as articulated in educational policy. A review of arrangements for curriculum planning and coordination 
may enable the school to identify creative approaches within the new programme that could fruitfully be applied in other areas. "Teachers do not work together to plan curriculum matters, because they are not properly trained or workshopped" (P3).

"I try to promote collaboration with urban schools and to encourage mutual responsibilities among rural teachers, but without any success" according to P7. Teachers rely on the briefest of notes handwritten on scratch pads and do not follow lesson plan guidelines. Writing daily lesson plans is a large part of being organised. Many activities precede the process of designing and implementing a teaching/lesson plan. The job of teachers in systematic lesson planning is not complete until the learners' attainment of the anticipated outcomes and effectiveness of the lesson in leading learners to these outcomes has been assessed.

For many learners in rural areas, English is a foreign language heard only at schools. For most of the teachers too, English is a second language. The use of English as a medium of instruction is often yet a further barrier to learning for rural learners.

"It is a bad system that does not make mother-tongue instruction the norm in public schools" according to P8. According to Monk \& Carlson (1992) the preparation of teachers is more limited in rural districts.

We must develop a better understanding of the circumstances in which our learners live before we can decide what to teach them.

\subsection{Challenges of poverty}

The effects of poverty have been demonstrated on many aspects of life, from education to health, life outcomes to selfesteem. Any discussions regarding education and how school variables affect students' attainment of education cannot be divorced from poverty, which encompasses poverty of the learners, their families, and the community that inevitably leads to poverty of the school. (Cohen \& Barnes, 1999, p23)

Rural schools in the researched area of Mpumalanga experience poverty and its detrimental effects. Being classified as high poverty or low socio-economic status school conjures up many images in people's minds, as well as evidence to support some of people's conceptions.

Poor funding in rural schools is one of the greatest challenges faced by rural education. The low proportion of funds that are allocated to rural education is worrisome as it has been suffering from a bigger financial shortfall over the past few years. Shrinking spending on rural schooling has caused widespread problems in both students' enrolment and teacher commitment to teaching. Besides, quality (Morgan, et el, 2006) of outcome, maintenance of facilities, have also suffered considerably because of poor allocation of funds and other educational resources to rural schools.

"I get the impression that if you are a rural school, people think you can cope, you haven't got that many learners to deal with, so you don't need extra resources. You should just get on with it" (P4).

"I think we are disadvantaged from a perception of poverty. We are so insignificant as to not matter very much... So you think, why bother" (P3).

"Many families are unemployed and do not have any income to support the school financially. We suffer to do anything extra to improve the school" according to P5.

"Families depend on grants to survive every day and we feed the children at school so that they at least get one meal a day" (P2).

Poverty is an issue that more and more of our nation's children are coming face to face with. The price that children of poverty must pay is unbelievably high. Increasing numbers of children enter rural schools with needs from circumstances, such as poverty, that schools are not prepared to meet.

Poverty is considered a major at-risk factor (Leroy \& Symes, 2001). Some of the factors related to poverty that may place a child at-risk for academic failure are: very young or low educational level parents; unemployment; abuse and neglect; substance abuse; dangerous neighbourhoods; homelessness; mobility; and exposure to inadequate or inappropriate educational experiences.

High-mobility is a system of poverty and its surrounding factors. "Learners of poverty live in places that are rent by the week or even per day" (P4). They move from rural area to town and back as parents' searches for work or runs from problems. Moving around is a very emotional event for rural learners. Their school attendance is often irregular. 
"Children in rural schools cannot make friends. With regard to both the academic and social aspects of school, they may figure, "Why bother? I am just going to move again" (P8).

A good education is often the only means of breaking the cycle of poverty for rural learners.

\subsection{Technology challenges:}

Many areas in the country do not have the high-speed delivery systems needed to make online technologies work best. Many rural schools do not even have a budget to purchase any form of technology. And, in some cases, rural schools do not have the capacity to use the technology available.

"I have never touched any form of technology in my school" according to P2.

"Magazines and newspapers are scares in our area, how will we cater for computers?" (P5).

At the same time, rural schools are hours away from a university and too remote for universities to provide fieldbased learning. Mpumalanga does not have a university.

\subsection{Problems of access in rural schools:}

Children who never attended school are often those in the least developed rural areas. Many factors contribute to lower educational participation in rural areas. Some of these factors on the demand side of education while others are on the supply side. On the demand side, rural children are less interested in attending school. First (Lockheed \& Verspoor, 1991) the opportunity costs of attending school are often higher in rural areas. Many rural households (in some areas of Nelspruit and White River as well) depend on their children for help during busy times of the agricultural year. Schools are usually designated to follow a rigid schedule in terms of both time of the day and term dates and often expect learners to be in school during busy periods of the agricultural calendar, according to Taylor \& Mulhall (2001). Parents in rural areas often have a lower level of education attainment and may attach a lower value to schooling.

"Parents are not able to help their children with homework or preparing for tests, because of their low level of education"

(P6). If parents are not educated themselves, they will have less ability to provide educational support for their children.

Homes in rural areas are often ill-equipped to meet the educational needs of children and often lack facilities like electricity. Children have less parental encouragement to go to school. When learners attend school, they find the curriculum less relevant and attractive to their lives, and learners may receive less support for their learning from home.

\subsection{Lack of resources}

Many financially strapped rural schools in the researched area must often deal with aging facilities and limited funding for new equipment and technology.

"We sometimes feel that we are the dumping ground of second hand equipment not used in the town schools" (P3).

"Rural schools will never be successful if our schools are not provided with books, computers, technology and safe transportation. We suffer a lot" (P2).

Partnerships with local businesses are difficult, because so many schools must compete for sponsors and the local businesses are also suffering with the poverty problem.

Parents can be critical partners for the school in identifying external funding sources, but in rural schools parents are not involved (maybe because of their low level of education) and school governing bodies are dysfunctional.

For many rural schools the quality of schools has a direct impact on the economic success of the community. To guarantee both the stability of rural communities and our nation's ongoing competiveness in the global market, it is more important than ever to ensure that all rural school learners pass with the skills they need for university, careers and life. But then rural schools must be equipped with the necessary resources to meet the goals of the twenty-first century. 


\section{Recommendations}

Different challenges and opportunities abound in every rural schools community. These challenges and opportunities often are left unattended by policymakers and others. Yet there is little that our nation can do to change our overall education picture of it leaves behind rural schools, learners and communities.

The study concludes with recommendations to improve the conditions of rural schools in Mpumalanga but also other rural schools in South Africa and perhaps Africa. We need to find solutions to meet the Education for All goals in making recommendations to improve the conditions of teachers and teaching in rural schools.

- Research has shown that the quality if teachers in our classrooms is the most important school-related factor in boosting learners' achievement (Lewin, 2004). Therefore, policymakers must put mechanisms in place to support and promote the retention of qualified and competent teachers in rural schools with a view to improve the quality and working conditions of teachers in rural schools. To attract and retain teachers in isolated communities, they should be compensated with additional financial incentives, in the form of hardship allowance, travel allowance for teachers to go to rural areas.

- The effectiveness of rural schools in producing quality learners lies in a good teaching environment. This is a missing gap that the government must fill to enable rural schools to face the challenges. Beyond rhetoric and statements on the education of our country, the government must be actively involved in the upgrading and development of rural schools. Although they are statements by the government that they recognised the importance of teachers, the reality on the ground is that teachers are continuously treated as second class workers and their status have continued to be at risk. The commitment to education in rural schools can be revealed through adequate provision of financial and human resources to rural schools.

- Further, teachers should be able to utilize information communications technology (ICT) as teaching and learning tools. ICT and open and distance education programmes can be used to expand and enhance learning opportunities for allowing them access courses not available in their school and interact with learners attending schools in other communities. If electricity is still not accessible, alternative sources of generating electricity can be explored. Therefore, to achieve the Education for All goals, the government must urgently address the issue relating to the provision of adequate infrastructural facilities and teacher capacity building.

- Government must act to guarantee the safety of learners and teachers in rural schools. Rural schools also struggle with drug and alcohol abuse, teen pregnancy, and gang activity. Parents must also be encouraged to help to tackle these issues in the school. After school programs are one way rural schools and communities can work together to provide a safe place for learners and to build on classroom learning.

- A good education is often the only means of breaking the cycle of poverty for poor children. These children need an education that is founded in high standards and high expectations for all. Being able to identify and understand learners who are at-risk is critical if we are to support their growth and development.

- Principals in rural schools have more than their fair share of work. Principals in rural schools are overloaded and need more assistance to serve the schools in the manner best serving the learners. School districts must step up to the task of providing more assistance to the rural school principal. Local leadership should include professional development training and support for principals to attend workshops and conferences (Rudi \& Whetstone, 2008).

\section{Conclusion}

Rural schools constitute a significant proportion of South African schools and schools districts. So it is imperative that their needs are taken into account. The government cannot singlehandedly solve every educational problem in rural settings. But it can leverage its role in ways that improve outcomes for the nation's learners in rural geographic areas. The promise of education law is to ensure that all learners have equal access to a high quality of education. That promise cannot materialize if certain geographic segments of the population are not equitably served by the education system.

If we do not take a step up, Education for All and the Millennium Development Goals, will only remain a dream.

\section{References}

Alexander, N.A. (2002), Race, Poverty and the student curriculum: Implications for standards policy. American Education Research Journal, 39, 675-693.

Akyeampong, K, \& Stevens, D. (2002). Exploring the backgrounds and shaping of beginning student teachers in Ghana: toward greater 
contextualisation of teacher education. International Journal of Educational Development 22 (3-4): 262-274.

Alspaugh, J.W. (1998). The relationship of school and community characteristics to high school drop-out rates. The Clearing House, 71(3), p.184-188.

ANC. (1995). A policy framework for education and training. Swaziland: MacMillan.

Brown, D.L. (2003). Challenges for rural America in the $21^{\text {st }}$ Century. University Park PA: Pennsylvania State University Press.

Buckingham, D. (2003). The rural principalship: For better or sores. In Gold Matters, Australian Primary Principals Association, 4(2), March 2003.

Castle, E.N. (1995). The changing American Countryside Rural People and Places. Kansas: University Press.

Cohen, D.K. \& Barnes, C.A. (1999). Research and purposes of Education. In E.C. Lageman \& L.S. Shulman (Eds). Issues in educational research: Problems and possibilities. San Francisco: Jossey-Buss Publishers.

Department of Education. (2005) Report of the Ministerial Committee on Rural Education. A new vision for rural schooling. Pretoria: DoE.

De Young, A.J. (1991). Rural Education: Issues and Practice. New York: Garland Publishing, Inc.

Harley, K. \& Wedekind, V. (2002). Political change, curriculum change and social transformation, 1990-2002. International Journal of Education Development, 20(4), 287-304.

Hedges, J. (2002). The importance of posting and interaction with the education bureaucracy in becoming a teacher in Ghana. International Journal of Educational Development, 22, 353-366.

Henning, E., Van Rensburg, W. \& Smit, B. (2004). Finding your way in Qualitative Research. Pretoria: Van Schaik.

Lewin, K.M. (2004). The pre-service training of teachers: Does it meet its objectives and how can it be improved? Background paper for EFA Global Monitoring Report 2005.

Lockheed, M. \& Verspoor, A. (1991). Improving Primary Education in Developing countries. Oxford University Press, World Bank.

Miller, R.L \& Brewer, J.D. (2003). The A-Z of Social Research. London: Sage Publications.

Monk, D.H. \& Huller, E.J. (1993). Predictors of high school academic course offerings: The role of school size. American Educational Research Journal. 30, 3-21.

Monk, D.H. \& Carlson, W.S. (1992). Rural/non-rural differences among secondary science teachers: Evidence of the longitudinal study of American youth. Paper presented at the annual meeting of the American Education Research association. San Francisco, CA.

Morgan, J., Atkin, C., Adedeji, S.O. \& Sieve, A. (2006). The condition of teachers and teaching in rural schools. Montreal: UNESCO Institute for Statistics. Mimeo.

Mulford, B. \& Johns, S. (2004). Successful School Principalship. Leading and Managing. Journal of the Australian Council for Educational Leaders, 10(1), pp. 45-76.

Mulkeen, A. (2005). Teachers for Rural Schools: A challenge for Africa. Working Paper. Biennale on Education in Africa (Libreville, March 27-31, 2006). Association for the development of education in Africa.

Msike, V. 2010. Rural school principals' quest for effectiveness: Lessons from the field. Journal of Education, No. 48, 2010.

Parks, G. \& Sher, J. (1979). Imaginary Gardens? Real problems. Las Cruces, NM. Eric document No ED-076.

Peters, J. \& Le Carnu, R. (2004). Leaders in transition: living with paradoxes. http://ww.leeds.ac.uk/educol/documents.

Polischuk, D.A. (2002). The impact of Leadership on School Culture: A critical connection. http://www.ucalgary.za/-distance/cll.

Republic of South Africa. (1996a). Constitution of the Republic of South Africa, Act 108 of 1996.

Republic of South Africa. (1996b). South African Schools Act, Act 84 of 1996.

Rude, H.A. \& Whetstone, P.J. (2008). Ethical considerations for special educators in rural America. Rural Special Education Quarterly, 27(2), pp 10-18.

Starr, K. \& White, S. 2008. The small rural school principalship. Key challenges and cross-school responses. Journal of Research in Rural Education, 28(5), pp1-12.

Taylor, P. \& Mulhall, A. (2001). Linking learning environments through agricultural experience - enhancing the learning process in rural primary schools. International Journal of Educational Development, 21, 135-148.

Terreblanche, M. \& Durheim. K. (1999). Practical Research: Applied methods for social research. Cape Town: University of Cape Town Press.

Towse, P., Kent, D., Osaki, F. \& Kirua, N. (2002). Non-graduate teacher recruitment and retention: some factors affecting teacher effectiveness in Tanzania. Teacher and Teacher Education 18, 637-652.

UNESCO. (2005). Education for all by 2015. Will we make it? EFA Global Monitoring Report 2008, Paris: UNESCO.

Wallin, D.C. \& Reimer, L. (2008) Educational priorities and capacity: a rural perspective. Canadian Journal of Education, 31(3), pp. 591613.

Wright, K.A. (2007). Reenergizing small communities: a vital role for rural schools. The Education Forum, 71(4), pp 345-360. 